\title{
Factors Influencing the Adoption of Mobile Phones among the Farmers in Bangladesh: Theories and Practices
}

\author{
Sirajul M. Islam and Åke Grönlund
}

\begin{abstract}
This paper investigates the factors influencing the adoption of mobile phone technology among farmers in Bangladesh. Electronic services are one important measure for rural development and mobile phones is the dominating cellular technology; hence understanding the adoption of this technology is important. The paper uses interpretive philosophy investigating adoption factors by means of survey data, participant observation and related studies on rural Bangladesh and technology acceptance. Based on a number of acceptance models from the literature, a conceptual Rural Technology Acceptance Model (RUTAM) was developed to analyze the arguments pertinent to a rural developing country context. The most salient modification, compared to earlier models, is that social influence plays a bigger role than technology at early stages of adoption. 'Tech-service promotion' and 'tech-service attributes' are introduced as external factors which affect the behavioral intentions of an individual by means of perceived usefulness (PU) and perceived ease of use (PEU).
\end{abstract}

Index Terms - Adoption, Bangladesh, Farmers, ICT4D, RUTAM, TAM

\section{INTRODUCTION}

$\mathrm{W}$ ith its more than 160 million people, Bangladesh ranks as the eighth most populous country in the world [1]. Out of 29 million households, $89 \%$ are situated in rural areas and $52 \%$ (15 million) account for agricultural farm households [2]. According to the World Bank [3], "Poverty in Bangladesh is primarily a 'rural phenomenon', with 53 percent of its rural population classified as poor, comprising about 85 percent of the country's poor". The rate of adult literacy at national level is $49 \%$, while it is $46 \%$ in rural areas. As surveyed by the BBS-UNESCO [4], around $26 \%$ of the poorest and $34 \%$ of the poor people in the rural areas have formal literacy.

Manuscript received July 7, 2010. Recommended by Prof. Maria Lee on January 19, 2011.

Sirajul M. Islam is with the Swedish Business School at the Örebro University, Fakultetsgatan 1, Örebro 70182, Sweden. (e-mail: sirajul.islam@oru.se).

Ake Grönlund is with the Swedish Business School at the Örebro University, Fakultetsgatan 1, Örebro 70182, Sweden. (e-mail: ake.gronlund@oru.se).
Although Bangladesh ranks one hundred thirty-eighth out of 154 countries in the ICT Development Index [5] in 2007, the penetration rate of mobile phones is remarkable compared to other ICT tools (e.g. PC, Internet etc.). Recent investigations show that around $45 \%$ of the total population - one out of (less than) three people, or at least one per family on average - has a mobile phone [6]. As the growth of the Bangladeshi economy depends on rural development, much attention needs to be paid to the agricultural sector and the farmers who are the main, yet one of the weakest actors in the economy [7], [8]. In the perspective of this paper, timely adoption and appropriate use of easily and widely available mobile phone technology in agricultural operations is one opportunity that may help in realizing the 'digital opportunities', enhancing rural productivity and hence contribute to reducing urban-rural inequalities. Although the agricultural trade and farmers have become an important target for mobile phone services, studies of technology adoption and the diffusion process in such contexts are currently scarce [9]. Kwon and Chidambaram [10] find that much of the variance in the studies of mobile technology use remains unexplained, and addressing this gap should be an important direction for future research. Kim and Garrison [11] suggest that the researchers should add more constructs to the existing acceptance models related to mobile technology as this kind of technology is constantly evolving and new factors are emerging every time.

Against this backdrop this paper aims primarily to investigate the factors influencing the adoption of mobile phone technology among the farmers in Bangladesh. The underlying purpose of doing so is to allow a better understanding of how to provide useful services to the farmers' community. To do so, we focus on the following issues:

- To explore earlier theories and models on technology adoption and diffusion;

- To develop a conceptual research model based on the literature studies;

- To investigate empirically the factors relevant to rural Bangladesh; and

- To detail the model based on the empirical findings and hence suggest the factors with associated variables especially relevant to rural people in developing regions. 
The findings from this study contribute to a larger picture of the technology adoption process in rural settings, specifically in Bangladesh. It can then potentially be transferable to other developing countries, particularly those who share a similar socio-economic and technological background.

\section{LITERATURE REVIEW}

Technology adoption is the decision of a group or individual to make use of an innovation. Beal and Bohlen [12] state that people accept new ideas through a series of complex mental processes in which adoption is the final action. Rogers [13] shows technology diffusion in a global perspective to match a classical normal distribution curve which can be explained by the demographic and psychographic characteristics of the adopters.

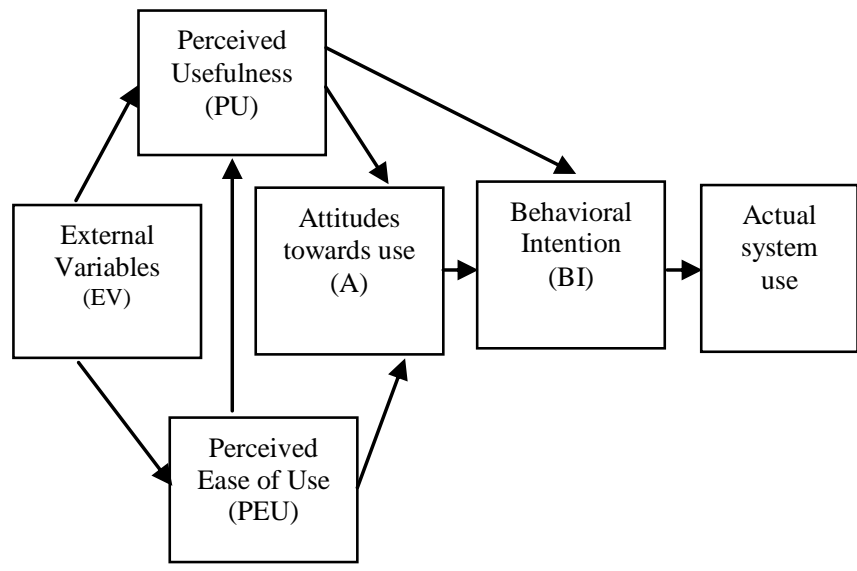

Fig. 1. Technology Acceptance Model (TAM) [14]

The Technology Acceptance Model (TAM; by Davis in 1989) as shown in Figure 1, initially developed for new enduser of information systems for organizations, is one of the most influential models in the study of technology use [15]. TAM explains the factors influencing the behavior of an individual regarding accepting and using new technology. Perceived usefulness (PU) is the key determinant of acceptance, meaning the user's 'subjective probability that using a specific application system will increase his or her job performance within an organizational context' [14]. Perceived ease of use (PEU), is 'the degree to which the user expects the target system to be free of effort' [14]. Together, PU and PEU determine the attitude (A) of a person towards using the system. Finally with the influence of PU and Attitude, Behavioural Intention (BI) influences the actual use of the system. However despite its robustness across populations, settings and technologies, Davis [16] later identifies the following key limitations of TAM.

- Static, cross-sectional, snapshot-oriented (individual level of analysis and limited span across causal chain).

- Emphasis on controlled, conscious processing (exclusion of automatic processing and overlooking multitasking).
- Limited account of social processes (knowledge collaboration and collective processes).

Malhotra and Galletta [17] argue that TAM is incomplete as it does not account for social influence in the adoption of new information systems, and therefore suggest to consider the effect of social influence on the commitment of the IS user. Furthermore, Mathieson et al. [18] remark that TAM has limitations in assuming that usage is voluntary and free of barriers that would prevent individuals from using an IS. Inclusion of social influence was indeed the motivation for TAM-2, proposed by Venkatesh and Davis [19]. TAM-2 provides a detailed account of the key forces of the underlying judgments of perceived usefulness, "explaining up to $60 \%$ of the variance in this important driver of usage intentions".

The Unified Theory of Acceptance and Use of Technology (UTAUT) by Venkatesh et al. [20] is a further development which combines some major theories (e.g. TAM, Theory of Planned Behavior, and Innovation Diffusion Theory) from the IS literature. The model has three direct determinants of intention to use (performance expectancy, effort expectancy, and social influence) and two direct determinants of use behavior (intention and facilitating conditions). There the intention and facilitating conditions are mediated by experience, voluntariness, gender, and age. Venkatesh et al [20] suggest that 'given that UTAUT explains as much as 70 percent of the variance in intention, it is possible that we may be approaching the practical limits of our ability to explain individual acceptance and usage decisions in organizations'.

\section{A. RUTAM- A Conceptual Research Model}

Based on the review of a number of theories pertinent to technology acceptance in general and mobile technology in particular, we have developed a conceptual research model for the research objectives as stated. This conceptual model (Figure 2), which can be known as the RUTAM - Rural Technology Acceptance Model, incorporates most of the major and commonly used factors in a summarized fashion.

A simplified version of RUTAM is also presented in Figure 3. So far, the Rural Area Technology Acceptance and Diffusion of Innovation Model (RuTADIM) proposed by Lu and Swatman [21] is the only model focusing on rural context, but it is devised in a developed country context. RuTADIM was developed specifically to investigate acceptance of mobile technology and the likely diffusion of a project called MobiCert in rural areas of South Australia. Although RuTADIM is not tested beyond the context in which it was developed, we have considered the two new external variables it proposes: 'Rural connectivity' and 'Access and Response time' under the 'facilitating conditions' in RUTAM. 


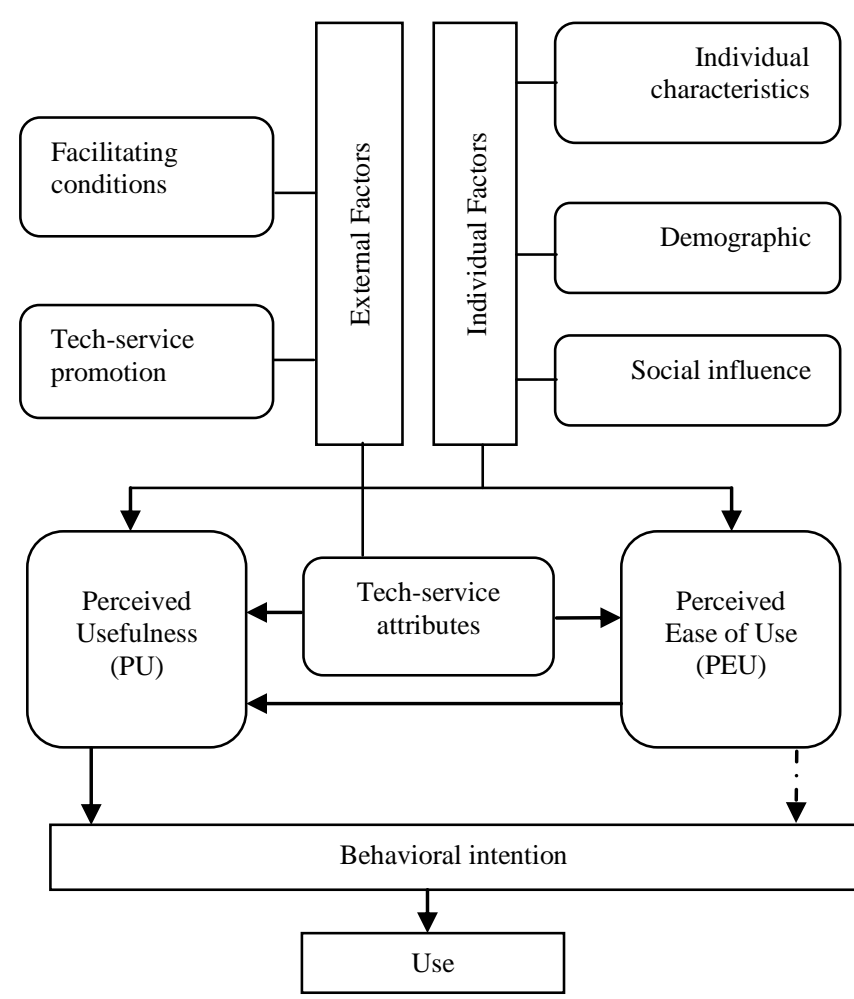

Fig. 2. The Rural Technology Acceptance Model (RUTAM)

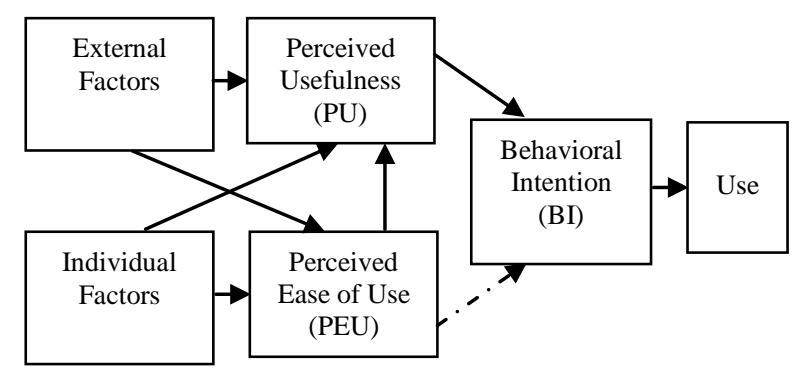

Fig. 3. Simplified version of RUTAM

It can be noticed that RUTAM is strongly influenced by the original TAM. The prevailing models express different views of the relations among the factors we adopted. Following the most recent models, we adopted a "social" approach in RUTAM, assuming that social influence is more important than technology itself. This is contrary to the original TAM but consistent with most of later models. Following that assumption, we tentatively distinguished between external and individual factors influencing PU and PEU.

Next we briefly describe the conceptual model RUTAM and the factors to be analyzed under each of the proposed constructs based on the literature pertinent to the use of new technology (e.g. mobile phones) and systems.

\section{1) Facilitating Conditions}

Venkatesh et al. [20] define Facilitating Conditions (FC) as 'the degree to which an individual believes that an organizational and technical infrastructure exist to support the use of a system'. Seneler et al. [22] describe FC as the support given to the users while interacting with the technologies, like learning the technology from a friend.
Jain and Hundal [23] argue that the choice of service provider is affected by the facilitating factors such as network coverage, service quality, easy availability of subscriptions and bill payment centers. The following list of variables is commonly found relevant to the mobile phone technology which can broadly be categorized as the 'facilitating conditions':

- Rural connectivity \& access time [21]

- Technological infrastructure [24], [25]

- Quality and availability of support services [23], [26]

- Market structure and mechanism [27], [28]

- Tax policy and distribution channel [25]

- Modes of payments [24], [25], [29]

\section{2) Tech-service Attributes}

Tech-service attributes (TA) refer to the properties or characteristics of a certain technology, system, or service that distinguish it from other technologies, systems or services. Adesina and Baidu-Forson [9] find that farmers' perceptions of technology characteristics significantly affect their adoption decisions. Dishaw and Strong [30] also argue that users' perceptions about ease of use and usefulness are likely to be developed from rational assessments of the characteristics of the technology and the tasks for which it could be used. Therefore, the variables related to this (TA) category are:

- Service Characteristics [31]

- Cost of handsets and services [21], [26], [32]

- Technology characteristics - Interface, Network Capabilities [33]

- Interface characteristics [23], [33]

- Brand reputation, Flexible technology (e.g. CDMA or GSM) [23], [34], [35]

\section{3) Tech-service Promotion}

While awareness is the individual's extent of alertness and ability to draw inference in a certain time and space towards an object or situation, influence is the process of creating this awareness. Kalish [36], characterizes awareness as one of the steps towards adoption and subsequently defines it as "the stage of being informed about the product search attributes" (p. 1569). Kotler and Armstrong [37] place awareness as the prerequisite of knowledge, liking, preference, conviction and purchase. Doss [38] finds that lack of awareness is one of the main reasons for farmers not adopting the new technology. Cook [39] therefore suggests that suppliers must promote their initiatives in order to create awareness among the users.

\section{4) Social Influence}

According to the Theory of Reasoned Action [40], [41], behavioral intention of a person is influenced by subjective norms which in turn are influenced by the significance of referents' perception (or normative beliefs) and motivation to comply with those referents. Stiff and Mongeau [42] find that the influence of social norms on individuals' behavioral 
intentions in some cases is stronger than the influence of attitudes. Sometimes, perception of societal norms may prevent a person's behaviour in accordance to his/her personal attitudes. In a rural context, Jain and Hundal [23] find that "the rural people [of India, authors' remark] had been found more influenced by the neighbors' usage [....... and media has been regarded as the negligible impact on the choice of buying a mobile phone". In addition to neighbors, there are some other sources of influence also evident in the literature, such as relatives, friends, and seniors or influential persons in the community [26], [31], [43].

\section{5) Demographic Factors}

There is a good number of studies describing the importance of the demographic context in use and adoption of new technology. According to those studies, variables that are important in this category are:

- Age [10], [23], [33]

- Gender [44]

- Culture and ethnicity [33], [45], [46], [47]

- Income and household [24], [48], [49]

- Occupation [10], [48]

- Education [24], [49]

Age is one of the most discussed demographic factors in the technology adoption literature. However, Mallenius [50] suggests that the "keyword should not be age, but rather, functional capacity" which addresses the capacity to use mobile devices and services. Richardson et al. [51] find, in a study on Grameen Telecom's Village Phone Programme in Bangladesh, that "higher expenditures for better service are more likely to come from younger phone users aged 20 to 30 , an age group that would more likely be receptive to a wider range of phone services, including card phones". Similarly, the Jain and Hundal [23] study among the rural people of India reveals that the majority of the users $(62 \%)$ of mobile phones are within the age group of 20 to 40 .

Considering the impact of culture on human behavior, Phillips et al. [52] argue that cultural affinity has a positive influence on technology adoption through perceived ease of technology use and therefore it is highly correlated with demand for products and services. On the other hand, Biljon and Renaud [47] find that "mobile phone uses have a unique set of cultural dimensions ..... that do not necessarily correspond to the culture that exist in human-human relations".

DiMaggio and Cohen [49] explain the positive correlation between the level of income and timing of adoption of new technology. He finds that availability of a technology infrastructure shapes inequality by place of location (urban verses rural) that makes income more important. Similarly, Kalba [24] argues that adoption of certain technology attributes or alternatives (e.g. fixed vs mobile connection and postpaid vs pre-paid services) depends on the level of household income over time. Furthermore, the rate of income depends on the type of occupation [10], [48] and therefore it is an important factor for the urgency and relevance of adopting a technology at a given time and within a specific cultural framework.

Education and income are closely related [53]; the more educated a person is, the greater is the likelihood of a high income. Also, more educated people are better able to learn and use new technology [49] and hence they are more likely to be innovative. With respect to farmers, Fuglie and Kascak [54] find that diffusion of new technology among this community is relatively slow due to their low education level. Yet, the Jain and Hundal [23] study on rural India exhibits that a majority of the mobile adopters have education level 'below metric $\left[10^{\text {th }}\right.$ class $]$ '.

\section{6) Individual Characteristics}

Sultan and Chan [55] argue that individual characteristics are more significant than technology properties in the technology adoption process in general. On the other hand, Wei and Zhang [56] find that in the rural context psychological factors in adopting a new technology and mobile phones in particular are less significant than behavioral factors. Such a phenomenon in a rural setting is probably the social influence on the adoption process which is stronger than individual characteristics [31]. Gatignon and Robertson [57] suggest that information processing capability is a factor that separates the adopters from the non-adopters. This capability is framed by the individual's extent of observability or awareness [48] [58], innovativeness [32], [59] and past adoption or usages experience [34]. Compatibility or apprehensiveness [32] [48], which is also an important determining factor, depends not only on a person's age, education and income but also on the relevance of the new technology with the task or job in a given time and place.

\section{7) Perceived Usefulness (PU) and Perceived ease of Use} (PEU)

Perceived usefulness (PU) and Perceived ease of use (PEU) are the most cited factors that influence the attitude and behavioral intentions of a person [14]. These two factors are also most significant in mobile service usages [31]. With regard to the usage of cellular phones, Kwon and Chidambaram [10] find that PEU has significant effects on users' extrinsic and intrinsic motivations, while apprehensiveness has a negative effect on intrinsic motivations. Gefen and Straub [15] argue that the importance of PEU is related to the nature of the task an individual is facing. PEU, therefore, directly affects the adoption of a device, such as a mobile phone, only when the person's primary task is to be done via such device. It is therefore also suggested that PEU is affected by actual use of the phone (i.e. after adoption), though the effect diminishes with the frequency of usages over time [60]. The following is a list of common factors related to PU as cited by many studies on mobile technologies:

- Perceived usefulness [26], [60]

- Job relevance [11], [21], [61] 
- Mobility [31], [43]

- New possibilities [62]

- Enjoyment [31], [62]

- Convenient/time saver [63]

- Productivity (save money and make more money) [63]

- Indispensible for business [63]

\section{8) Behavioral Intention and Use}

Attitude, as a significant factor in the process of adoption, is found in the original studies of TRA [40] and TAM [14], but has been excluded from many other studies, even the later versions of TAM. Where social norms and perceived usefulness are strong, a person's innate unfavorable attitude may disappear and behavioral intentions will become more consistent with the social trends in a certain time and context [31], [42]. As subsequent action for adoption is concerned, Sarker and Wells [33] find continuity of use over time and resource commitment as the two outcomes, while some other studies describe these two as 'actual use' [26], [60], [61].

\section{Methods}

This is an interpretive case study [64] aiming to investigate the factors influencing adoption of mobile phone technology among the farmers in Bangladesh for a broader purpose of offering a better understanding of how to provide useful information services to the rural communities in the developing regions as part of the process of overall rural development. This approach is particularly relevant to this study as it is "aimed at producing an understanding of the context of the information system [i.e. using and adopting mobile phones, authors' remark], and the process whereby the information system influences and is influenced by the context" [64]. Furthermore, the inductive thinking process in interpretive research provides a hypothesis with a goal 'not only to conclude a study but to develop ideas for further study' [65].

This paper investigates the situation by means of a mix of qualitative and quantitative data [65] where the researchers are, as required, directly involved in the process of collecting and analyzing the data. In this case one of the researchers was a 'passionate participant' [66] being a while the other one was a "distant observer". This "participant observation" approach with a "sense of detachment" [67], helped to achieve comprehensive insights about the social settings of the farmers in Bangladesh.

\section{A. Data Collection}

Secondary data was collected by means of a literature search and by analyzing the contexts and existing theories as advised by Walsham [64]. In this case, both academic and general search engines were used. A "snowball" approach [67] for locating relevant papers was also employed by checking the lists of references of the relevant papers found. For the empirical part of the study, we conducted several surveys over the period between November 2006 and June 2009 in rural Bangladesh, primarily to understand the agricultural market information systems and the use of mobile phones by the rural inhabitants, particularly the farmers.

Table I summarizes the surveys. The first survey [8] was aimed at an overall understanding about farmers and agricultural marketing channels of Bangladesh and at evaluating the effectiveness of government-initiated webbased agricultural market information systems (www.dam.gov.bd). The other two were done immediately before and after the test run of a mobile phone based agriculture market information system (AMIS) designed for the farmers in a number of remote villages in a northern district of Bangladesh

The questionnaires used had sections on demographics, personal situation, farming situation including methods and produce, information and market needs and habits, and views and preferences regarding media and communication technology. There were structured as well as open-ended questions. To allow comparison, several questions were identical across the surveys. As many farmers are illiterate, the questionnaires were completed by the interviewers. In addition to the questionnaires, data was collected by the first author by means of observations, interviews and conversations with the farmers, and by video and face to face discussions with the relevant actors in natural and formal settings.

TABLE I

RESEARCH SURVEYS IN BANGLADESH (NOVEMBER 2006 - JUNE 2009)

\begin{tabular}{|c|c|l|l|l|}
\hline Period & Sample size (N) & \multicolumn{1}{|c|}{ Respondents } & \multicolumn{1}{|c|}{ Methods } & \multicolumn{1}{|c|}{ Research focus } \\
\hline Nov.2006- Feb.2007 & $\begin{array}{c}1050 \\
\text { (350 from each } \\
\text { category) }\end{array}$ & $\begin{array}{l}\text { Farmers, wholesalers and } \\
\text { retailers from 13 (out of 64) } \\
\text { districts of Bangladesh }\end{array}$ & $\begin{array}{l}\text { Semi-structured interviews for } \\
\text { the supply side and structured } \\
\text { questionnaires for the demand } \\
\text { stakeholders. }\end{array}$ & $\begin{array}{l}\text { Government sponsored web-base } \\
\text { market information systems and } \\
\text { marketing channel }\end{array}$ \\
\hline Nov.2007-Feb.2008 & 420 & $\begin{array}{l}\text { Farmers from 50 villages of 13 } \\
\text { (out of 64) districts of } \\
\text { Bangladesh }\end{array}$ & $\begin{array}{l}\text { Structured and open-ended } \\
\text { questions. }\end{array}$ & $\begin{array}{l}\text { Demographics, personal and } \\
\text { farming situation including } \\
\text { methods and produce, } \\
\text { information and market, media } \\
\text { and communication technology }\end{array}$ \\
\hline Dec.2008 - Jan.2009 & 210 & $\begin{array}{l}\text { Farmers (who had mobile } \\
\text { phones) within the geographical } \\
\text { zone of the pilot project on } \\
\text { mobile phone based AMIS }\end{array}$ & $\begin{array}{l}\text { Structured and open-ended } \\
\text { questions }\end{array}$ & $\begin{array}{l}\text { All components of the research } \\
\text { model }\end{array}$ \\
\hline
\end{tabular}

resident closely acquainted with the farmers in Bangladesh, 


\section{B. Data Analysis}

Primary data were categorized according to the research objectives in general and the insights derived from the literature review. The categorized data were used to examine the existing concepts by a simple frequency analysis (i.e. percentage) and to establish some arguments based on the discussions, open-ended questions and observations. The comprehensive literature review and series of data collection efforts until the point of theoretical saturation in our study suffice the iterative and comparative characteristics of the qualitative research [68], [69]. Orlikowski [69] states that the resultant framework from the process of theoretical saturation would be empirically valid and should "generalize the patterns across the sites".

The literature review process followed the guidelines of Webster and Watson [70] and Oates [67] which are designed to lead to the proposal of a conceptual model that synthesizes and extends existing research. Concerning the technology adoption models, starting from Rogers' Innovation Diffusion Theory (IDT) [13] and Davis' Technology Acceptance Model (TAM) [11], data from the collected papers were compiled in accordance with commonly cited factors of adoption and most prominent variables, such as perceived ease of use (PEU) and perceived usefulness (PU). Sorted data was categorized in some "concept matrixes" [70], and subsequently explained by including concepts and aspects from relevant articles and surveys. Finally, the findings were summarized in a conceptual graphical model, called RUTAM, where each of associated variables is explained and rationalized by the theoretical and practical groundings.

\section{BANGLADESH CASE STUdY: RESUlTS AND DisCUSSION}

In the following, we present and discuss our empirical findings, observations, and related studies on the farmers in Bangladesh using the factors as discussed in our conceptual model.

\section{A. Facilitating Conditions and Technology-service} Attributes

According to Bangladesh Telecommunication Regulatory Commission (BTRC) [6], mobile phone density in Bangladesh is now around $45 \%$, to be compared with a mere $1 \%$ in 2003. This rapid growth started in 1997 with the abolishing of the monopoly enjoyed by a company, Citycell, which uses CDMA technology. Under this monopoly, the cost of a mobile subscription was more than USD 1500 and network coverage was limited to only three metropolitan areas - Dhaka, Chittagong and Rajshahi. GrameenPhone (GP, "the village phone") came into the market with their GSM technology right after the abolishment of the monopoly and within six years of operation it became the first operator in Bangladesh to reach one million subscribers. The fast expanding network, cheap fees and subscriptions, flexible technology and payment options (e.g. GSM vs CDMA, prepaid vs postpaid service) and offering many value added services (VAS) have rapidly made GP a market leader. Subsequently, the heavy competitive pressure among the six market players has led to reduced subscription cost to only around USD 25 - a reduction of more than $98 \%$ since 1997.

Table II shows technology attributes of the mobile phones used by the farmers. It indicates that rural people primarily prefer the network operators and handset providers respectively who have better networks and affordable prices with positive reputations. The Nokia 1000 series dominated the market. In fact, the Ultrabasic model Nokia 1100 is one of the most popular cell phones in the world as well [71].

TABLE II

TeChNOlogy Attributes of THE Mobile PhONES USED

\begin{tabular}{|c|c|c|}
\hline Category & Features & $\begin{array}{c}\text { Responses, } N=210 \text {, Year } \\
2009\end{array}$ \\
\hline Handset brand & Nokia & $\begin{array}{c}80 \% \\
\text { (Of which 95\% is } \\
\text { Ultrabasic } 1000 \text { series.) }\end{array}$ \\
\hline \multirow{5}{*}{$\begin{array}{l}\text { Reasons for } \\
\text { buying a } \\
\text { particular brand }\end{array}$} & Affordable price & $40 \%$ \\
\hline & $\begin{array}{l}\text { User friendly } \\
\text { interface }\end{array}$ & $30 \%$ \\
\hline & $\begin{array}{l}\text { Long-lasting battery } \\
\text { capacity }\end{array}$ & $12 \%$ \\
\hline & Reputation & $8 \%$ \\
\hline & Easy availability & $8 \%$ \\
\hline $\begin{array}{l}\text { Operators } \\
\text { subscribed }\end{array}$ & Grameenphone (GP) & $\begin{array}{c}95 \% \\
\text { (Out of a choice of six } \\
\text { operators). }\end{array}$ \\
\hline $\begin{array}{l}\text { Subscription } \\
\text { period }\end{array}$ & 2006 and 2007 & $60 \%$ \\
\hline $\begin{array}{l}\text { Subscription } \\
\text { type }\end{array}$ & Pre-paid & $100 \%$ \\
\hline \multirow{3}{*}{$\begin{array}{l}\text { Main reasons of } \\
\text { subscribing GP }\end{array}$} & $\begin{array}{l}\text { Better network } \\
\text { (stability) }\end{array}$ & $40 \%$ \\
\hline & Affordable price & $35 \%$ \\
\hline & Reputation, VAS & $25 \%$ \\
\hline \multirow{3}{*}{$\begin{array}{l}\text { Service } \\
\text { facilities } \\
\text { received from } \\
\text { the operators }\end{array}$} & $\begin{array}{l}\text { Flexible payment } \\
\text { options. }\end{array}$ & $80 \%$ \\
\hline & $\begin{array}{l}\text { Customer services on } \\
\text { demand }\end{array}$ & $80 \%$ \\
\hline & $\begin{array}{l}\text { Ample availability of } \\
\text { retailers for refilling } \\
\text { talk-time and the } \\
\text { ability to sign up for } \\
\text { a new subscription } \\
\text { locally }\end{array}$ & $75 \%$ \\
\hline
\end{tabular}

Our survey (Table II) also found that most of the phones were owned during the period between 2006 and 2007. Nationwide statistics also shows that the mobile penetration rate soared by around $250 \%$ from $6 \%$ in 2005 to $15 \%$ in 2006 [6]. There could be three possible reasons behind such growth; (a) government's reduction of import tax on mobile phone handsets from Tk. 1,500 (US\$25) to Tk. 300 (US\$5) in mid 2005, (b) reduction of tax on SIM/RIM from Tk. 1,300 (US\$20) to Tk. 800 (US\$12) in 2006, and (c) initiation of competitive airtime tariffs with flexible payment options (e.g. prepaid service). 


\section{B. Tech-service Promotion and Social Influence}

The presence of adequate awareness is one critical success factor for acceptance. For example, we found in our 2007 survey [8] that less than $1 \%$ of the farmers had heard about the existence of the government sponsored web-based agriculture market information service (www.dam.gov.bd). Whether or not the service was useful to farmers or not, clearly government had failed to promote its existence among the farmers.

TABLE III

SOURCES OF AWARENESS PRIOR TO SUBSCRIBING TO MOBILE SERVICES

\begin{tabular}{|l|l|c|}
\hline Category & Influences & \multicolumn{1}{|c|}{$\begin{array}{c}\text { Responses, } \\
\text { N= 210, Year 2009 }\end{array}$} \\
\hline Social norms & Community use & $65 \%$ \\
\hline $\begin{array}{l}\text { Reasons of choosing } \\
\text { the brand of handsets } \\
\text { (not mutually } \\
\text { exclusive) }\end{array}$ & $\begin{array}{l}\text { Human influence } \\
\text { (friends, relatives, } \\
\text { neighbors, and other } \\
\text { early adopters). }\end{array}$ & $75 \%$ \\
\cline { 2 - 3 } & $\begin{array}{l}\text { Media influence } \\
\text { (Radio, TV and } \\
\text { newspapers). }\end{array}$ & \\
\hline \multirow{2}{*}{$\begin{array}{l}\text { Reasons of choosing } \\
\text { the operators } \\
\text { (not mutually } \\
\text { exclusive) }\end{array}$} & $\begin{array}{l}\text { Human influence } \\
\text { (friends, relatives, } \\
\text { neighbors, and other } \\
\text { early adopters). }\end{array}$ & \\
\cline { 2 - 3 } & $\begin{array}{l}\text { Media influence } \\
\text { (Radio, TV and } \\
\text { newspapers). }\end{array}$ & \\
\hline
\end{tabular}

Table III exhibits the sources of awareness prior to subscribing to mobile services, which clearly points to a strong social influence. Although the choices of handsets and operators are distinct to each other, they are typically marketed together and often purchased at the same time. The above findings suggest that for both handsets and operators, social influence is more important than the media influence. We also found that $32 \%$ of the farmers (Table VI) in our sample have an education level above class ten, which matches the percentage of farmers being influenced by media while subscribing and buying the phones. In fact, it has been observed that media influence is strong among the early adopters who are apparently more of risk takers. In reality in rural Bangladesh, this group also acts as referents to others having less or no education.

As discussed in the literature review, 'individual factors' is an important influencing part of mobile phone adoption in a rural context. In fact, how the external factors are impacting upon a person depends on the individual factors which are comprised of individual and demographic characteristics, and extent and type of social influences.

\section{Demographic Factors}

$$
\text { 1) Age }
$$

Table IV shows that people between 19 and 30 are the most prone to mobile phone usage in 2009 , but the age group 31 50 is not far behind and in fact they were the most frequent phone owners in 2008. The age group 19-30 is generally seen as the most important target group.
TABLE IV

SURVEY RESULTS - AGE

\begin{tabular}{|l|c|c|}
\hline $\begin{array}{l}\text { Age level } \\
\text { (Those have mobile } \\
\text { phones) }\end{array}$ & $\begin{array}{c}\mathbf{2 0 0 9} \\
\mathbf{N = 2 1 0}\end{array}$ & $\begin{array}{c}\mathbf{2 0 0 8} \\
\mathbf{N = 1 5 5}\end{array}$ \\
\hline $18^{\text {th }}$ and below & $7 \%$ & $0 \%$ \\
\hline $19^{\text {th }}-30^{\text {th }}$ & $47 \%$ & $25 \%$ \\
\hline $31^{\text {st }}-50^{\text {th }}$ & $40 \%$ & $47 \%$ \\
\hline $50^{\text {th }}$ above & $6 \%$ & $28 \%$ \\
\hline
\end{tabular}

2) Gender

According to the UN-FAO [72], there are around $49 \%$ females and $52 \%$ males in Bangladesh. Women have a nearly $50 \%$ lower adult literacy rate than men and constitute around $46 \%$ of the farming population. The female share of non-agricultural wage employment in 2002 was $25 \%$ [73]. There is a lack of literature describing to what extent women are mobile phone subscribers and users. The authors of this paper did not survey the gender ratio of mobile phone use in rural villages, but a general observation is that it is mainly dominated by men. In fact, we did not find any female farmers having mobile phones in our sampling. There is so far an only one study Hultberg [44] on Bangladesh that shows that men make $70 \%$ of the mobile calls, which indicate a distinct gender difference.

3) Culture

Almost $90 \%$ of Bangladesh's population shares the same language, culture and religion. Therefore, we did not find any noticeable characteristics or activities that can distinguish the adopters from the non-adopters in terms of their prevailing human culture. An interpretation of this observation could be the cultural homogeneity at the national level and socio-economic homogeneity at the rural level. According to Khan et al. [74], "except for the [small] tribal areas in the Chittagong Hill Tracts, Bangladesh is a homogeneous country in which all rural areas are generally similar".

\section{4) Income and Households}

TABLE V

SURVEY RESULT - FARMERS' MONTHLY INCOME

\begin{tabular}{|c|c|c|}
\hline $\begin{array}{c}\text { Monthly income level } \\
\text { (household) } \\
\text { (Those who have mobile } \\
\text { phones) }\end{array}$ & $\begin{array}{c}\mathbf{2 0 0 9} \\
\mathbf{N = 2 1 0}\end{array}$ & $\begin{array}{c}\mathbf{2 0 0 8} \\
\mathbf{N = 1 3 5}\end{array}$ \\
\hline US\$ 84 and below & $72 \%$ & $62 \%$ \\
\hline US\$ 85-145 & $22 \%$ & $27 \%$ \\
\hline US\$ 146-215 & $6 \%$ & $2 \%$ \\
\hline US\$ 215 above & $0 \%$ & $9 \%$ \\
\hline
\end{tabular}

(1US\$ = BGD Taka 70 approximately)

Table $\mathrm{V}$ indicates that, not surprisingly, the income level in our sample was very low and most people are poor according to the national statistics [2]. According to this table, $72 \%$ have a monthly household income of less than USD 84. This suggests that mobile technology in rural Bangladesh has been significantly spread even in the lower income groups. It further suggests that except as concerns 
the choices of certain technology attributes (fixed vs mobile, post vs pre-paid, basic vs. advanced features etc.) and timing of adoption, income is not an important factor for the adoption and use of mobile phones in rural Bangladesh.

\section{5) Education}

According to the survey (Table VI), a majority of the farmers $(68 \%)$ have an education level below the metric (class 10) or secondary schooling taught in native language (Bangla) and 25\% have no formal education. It has been observed that those who do not have any formal literacy are able to access the mobile phone interface by memorizing the signs or symbols instead of the letters. This at least suffices to be able to perform basic operation of the phones.

6) Individual Characteristics

TABLE VI

SURVEY RESULT - FARMERS' EDUCATION LEVEL

\begin{tabular}{|l|c|}
\hline $\begin{array}{l}\text { Education level } \\
\text { (Those have mobile phones) }\end{array}$ & $\mathbf{2 0 0 9 ,} \mathbf{N = 2 1 0}$ \\
\hline No formal education & $25 \%$ \\
\hline $1-10$ th Class & $43 \%$ \\
\hline Secondary School & $15 \%$ \\
\hline Higher Secondary & $14 \%$ \\
\hline Graduate & $3 \%$ \\
\hline
\end{tabular}

A person who has high self-efficacy achieves compatibility towards adopting a new technology over time by exerting the required efforts. However in general, such self-efficacy among the farmers in Bangladesh is apparently low and therefore the influences of social norms are relatively higher. According to our 2009 survey, around $85 \%$ of the farmers opined that use of mobile phone had become a part of their daily lives. This opinion, and our overall observation, suggests that a particular buying behavior (i.e. extravagance) exists which is contradictory to the traditional pattern of (positive) correlation between income and consumption. People even manage to buy a mobile phone by taking loans from others or by saving money at the cost of sacrificing consumption of other essential goods.

Examining farmers' intentions prior to deciding whether or not to buy a mobile phone, our 2009 survey $(n=210)$ shows that farmers exhibited moderate innovativeness and a low level of individual uniqueness. They also had a need for cognition, and dependence on visualization rather than verbalization prior to using and adopting anything. A study by Islam et al. [7] also found that "Education, family size, farm size, annual income, farming and living expenditure, innovativeness, communication exposure, organizational participation and, aspiration were positively correlated with their use of information system".

\section{7) Perceived Usefulness and Perceived Ease of Use}

Although the numbers presented in tables VII and VIII are on post-adoption data, they provide some indications for PU and PEU of the users. According to Table VII, almost all farmers opined that use of mobile phones makes their daily lives easier mainly due to its mobility characteristics. It helps overcoming barriers of time and location and improves productivity. On the other hand, Table VIII indicates that the English language is a major problem in accessing the interface and contents of the services.

TABLE VII

FARMERS' PERCEIVED USEFULNESS (PU)

\begin{tabular}{|l|c|}
\hline \multicolumn{1}{|c|}{$\begin{array}{c}\text { Farmers' Perceived Usefulness } \\
\text { (PU) for Mobile phone usages }\end{array}$} & $\begin{array}{c}\text { Agreed } \\
\mathbf{N = 2 1 0}, \mathbf{Y r}=\mathbf{2 0 0 9}\end{array}$ \\
\hline Makes the life easier & $97 \%$ \\
\hline Useful in daily lives & $95 \%$ \\
\hline $\begin{array}{l}\text { Mobility (overcoming time and } \\
\text { location barriers) }\end{array}$ & $83 \%$ \\
\hline $\begin{array}{l}\text { Productivity (by saving money and } \\
\text { making more money) }\end{array}$ & $80 \%$ \\
\hline
\end{tabular}

TABLE VIII

FARMERS' PERCEIVED EASE OF USE (PEU)

\begin{tabular}{|l|r|}
\hline Statements & Responses \\
\hline $\begin{array}{l}\text { It is so interesting to access the SMS } \\
\text { and Internet features }\end{array}$ & $\begin{array}{r}\text { Disagreed }=57 \% \\
(\mathrm{~N}=210, \text { Year }=2009)\end{array}$ \\
\hline $\begin{array}{l}\text { Features of mobile phone seem } \\
\text { uncomfortable to use }\end{array}$ & $\begin{array}{r}\text { English \& SMS = All } \\
\text { Making call : None } \\
(\text { Year }=2009)\end{array}$ \\
\hline Do you access Value Added Services? & $\begin{array}{r}\text { No }=75 \% \\
(\mathrm{~N}=155, \text { Year }=2008)\end{array}$ \\
\hline
\end{tabular}

However, when they receive SMS, they use to seek help from their family members, neighbors or friends to interpret it. This indicates that due to strong social influence and perceived usefulness, linguistic and other operational barriers do not discourage people from using a service they deem to be useful. In fact, over time, users would be able to overcome the basic barriers that they initially thought of and faced in.

8) Behavioral Intention and Use

Table IX shows that the affective attitudes [75] in the form of trialability [13] or experiments [33], [60] apparently have little impact on the behavioral intentions of the farmers. Most of the users do not intend to change either operator or handset. However, some of the subscribers have intentions to change their handset probably either for enjoying better features as they already have achieved some operational skills or to buy brand new sets since many of them initially bought second hand sets from early adopters. Regarding the calling habits, a majority of the respondents make at least five calls a day, which can be considered as 'frequent users' given the low economic status of the group. Around $85 \%$ of these calls take place among relatives and friends, while the rest are mainly used for business purposes.

\section{Key Findings}

TABLE IX

FARMERS’ MOBILE PHONES USAgES BEHAVIOR

\begin{tabular}{|l|c|}
\hline Statements & Responses \\
\hline \multirow{2}{*}{$\begin{array}{l}\text { I will switch from my present phone } \\
\text { operator soon }\end{array}$} & $(\mathrm{N}=210$, Year 2009) \\
\cline { 2 - 2 } $\begin{array}{l}\text { I will change my existing mobile } \\
\text { handset soon }\end{array}$ & Disagree $=80 \%$ \\
\hline On average, how many calls do you & 1 to 5 calls $=47 \%$ \\
make in a day? & $6 \&$ above $=53 \%$ \\
\hline $\begin{array}{l}\text { On average, how many calls do you } \\
\text { receive in a day? }\end{array}$ & $\begin{array}{l}1 \text { to } 5 \text { calls }=27 \% \\
6 \& \text { above }=73 \%\end{array}$ \\
\hline
\end{tabular}


The following section details the key findings by populating the conceptual model (Figure 4) with the specific variables that our surveys, in combination with the arguments of related studies have found.

As for external factors, market structure, infrastructure and tax policy of the government are the three major facilitating conditions. Our evidence shows that mobile phone penetration rate increased dramatically during the time when the government abolished the monopoly in the telecommunication sector and reduced taxes on subscriptions and handsets. The network infrastructure (e.g. available base stations) is also a matter as it is directly linked to the 'network effect (or externality)'. Quick and wide expansion of the GP network created not only a positive effect on the customer base, but also created strategic advantages over other players in the market.

Tech-service promotion is an external factor influencing the process of individual awareness. This in fact is the promotion of products and services on part of the contents, products and service providers. Although, media influence among the farmers is not so great due to the low availability of media (TV, radio and newspapers) and low literacy level, it affects indirectly through referents as part of social influence process. In fact, Social influence turned out more powerful than promotional factors in our study. Farmers want to share the experience and rely mainly on educated family members, friends and neighbors who either are early adopters or have knowledge about the products and services. The tech-service attributes include network stability, cost of subscription for services, bill payment options, user friendliness of the handsets and brand reputations. This factor influences directly both on the PU and PEU of an individual. While facilitating conditions and tech-service promotion are more of indirect factors, tech-service attributes affect directly the decision making process of an individual. Tech-service promotions and tech-service attributes are two new additions to those found in the literature review of technology acceptance models.

The level of compatibility with the product and services, the extent of awareness in regard to the surrounding environment (e.g. what is going on around them, who is using what and why etc.), need for visualization rather than relying on words of mouth, and a tendency towards extravagant buying are the individual level characteristics of the farmers in Bangladesh. However, more or less, these characteristics are shaped and affected by a person's age, gender, occupation and education. We find that variances in age, gender and education are matters in regard to the nature and the extent of use and acceptance. In particular, we observed that the age group $19-30$ is the most frequent users. The gender bias is strong; users are predominantly male. The survey also reveals that education has effect only on the choices of services, not on the decision of buying a phone.

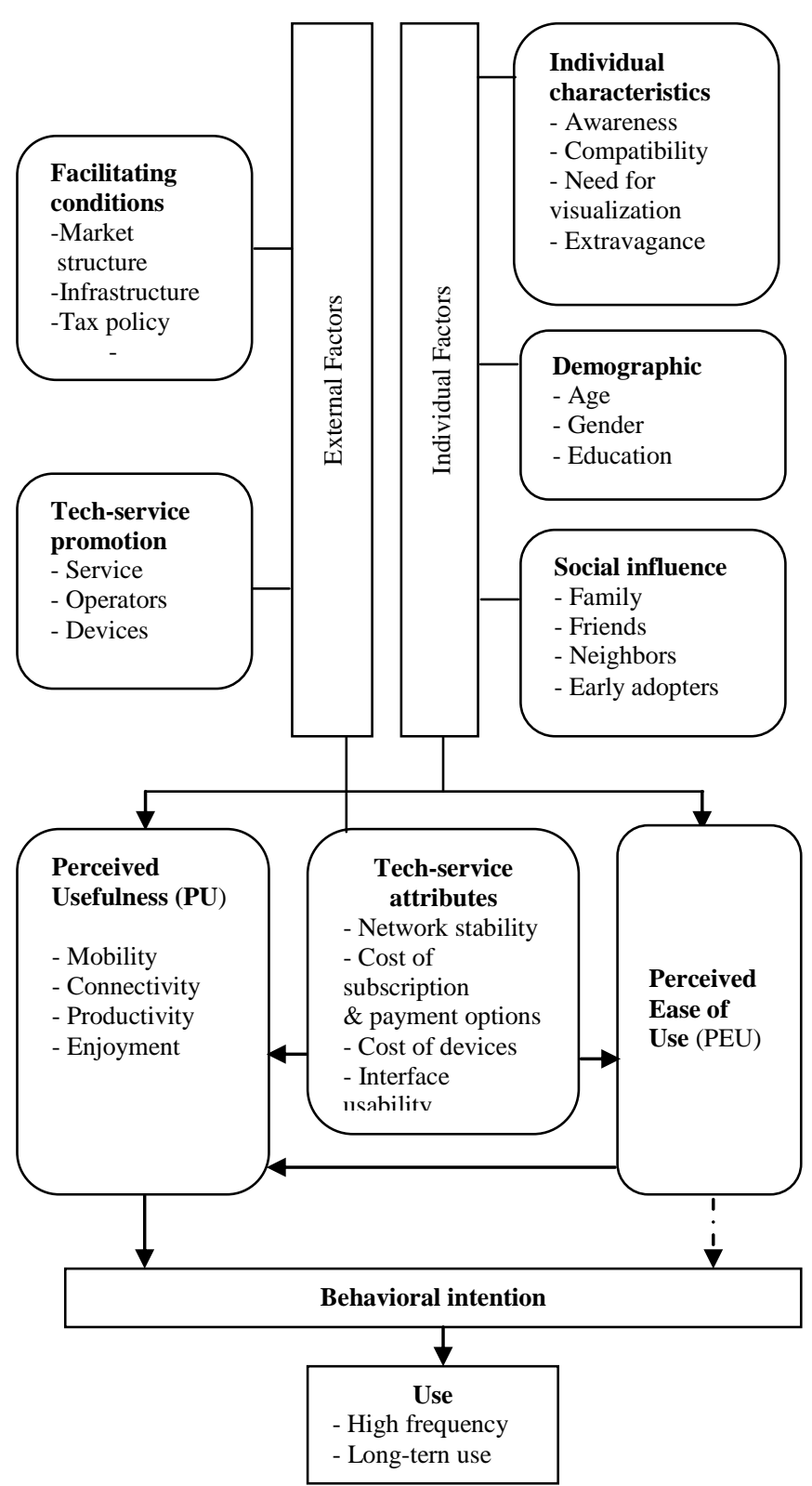

Fig. 4. Factors with associated variables in RUTAM influencing the adoption of mobile phones among the farmers in Bangladesh

Mobility, better means of connectivity with others, productivity in terms of saving money and increasing profits, and a sense of enjoyment are the major considerations that influence the perceived usefulness. Although lack of literacy seems to be a barrier to access to the interface, it does not seem to deter an individual from using the services as and when required. We also observed that even users who do not have electricity used the mobile phones. They used to charge their handsets at neighbors' houses or a nearby rural market. This suggests a strong social influence and high perceived usefulness. It further indicates that while PEU is indeed a factor, PU is more important (as shown by dotted in Figure 4)

Finally we find that despite the presence of socio-economic constraints, farmers are frequent users and have a low tendency to switch from one product or service to another. 


\section{CONCLUSION}

This paper has explored earlier theories and models on technology adoption and diffusion and summarized them into a conceptual research model, which has not been done before so comprehensively. We have detailed and rationalized the factors by means of empirical data and studies related to rural Bangladesh. The conceptual model populated with some factors as presented here can be useful for policy makers, service and technology designers and marketers, and researchers having particular interest to serve rural communities in developing regions. The inclusions of two new external factors - 'tech-service promotion' and 'tech-service attributes' - may be of special interest for the researchers devoted to technology acceptance and diffusion models.

One limitation is our study is of course that we have not provided any formal testing of the RUTAM. We have provided empirical findings to validate the contents and the logic of it based on relatively a small sample size. In fact, the present version of RUTAM is a hypothesis which can be considered as the first step of extending the prevailing TAM, specially fitted for rural people in poor countries. In this case, a formal testing in a larger sample would be one direction of future research. Strictly speaking we are not generalizing the results, but we still believe that the findings can be used, with caution, in other countries having similar socio-economic and technological contexts.

\section{REFERENCES}

[1] United Nations Department of Economic and Social Affairs (UNDESA), "World Population Prospects: Selected Demographic Indicators: Population - 2010”. Population Division, UN, New York, 2009. http://esa.un.org/unpd/wpp2008/tab-sorting population.html.

[2] Bangladesh Bureau of Statistics. Statistical Yearbook. Bangladesh Bureau of Statistics (BBS), Government of Bangladesh, Dhaka, 2009

[3] Bangladesh: Priorities for Agriculture and Rural Development. World Bank, 2010. http://go.worldbank.org/770VR4DIU0.

[4] Bangladesh: Literacy Assessment Survey-2008. Bangladesh Bureau of Statistics \& UNESCO, 2008. http://www.unescodhaka.org/downloaddocument/literacy-assessment-survey-2008.

[5] Measuring the Information Society: ICT Development Index 2009. ITU- International Telecommunication Union, Geneva: ITU, 2009

[6] Mobile phone subscribers in Bangladesh. Government of Bangladesh. Bangladesh Telecommunication Regulatory Commission (BTRC). Dhaka,

2010. http://btrc.gov.bd/newsandevents/mobile_phone_subscribers.php.

[7] M.S. Islam, M. E. Uddin, and M.U. Rashid, "Use of Knowledge System in the Rural Community in Improving Livelihood Status of the Farmers under RDRS". Journal of Agriculture \& Rural Development, vol. 5, no. 1\&2, pp. 167-172, 2007.

[8] M. S. Islam and $\AA$. Grönlund, "Agriculture market information eservice in Bangladesh: A stakeholder-oriented case analysis". LNCS Series, 4656/2007:167-178, Germany: Springer, 2007.

[9] A.A. Adesina and J. Baidu-Forson, "Farmers perceptions and adoption of new agricultural technology: evidence from analysis in Burkina Faso and Guinea". West Africa Agricultural Economics, vol. 13, pp. 1-9, 1995.

[10] H.S. Kwon and L. A. Chidambaram, "Test of the Technology Acceptance Model, the Case of Cellular Telephone Adoption". Proceedings of the 33rd Hawaii International Conference on System Sciences, USA, 2000.
[11] S. Kim and G. Garrison, "Investigating mobile wireless technology adoption: An extension of the technology acceptance model". Information Systems Frontiers, vol. 11, no. 3, pp. 323-333, 2008.

[12] G.M. Beal and J. M., Bohlen, "The Diffusion Process". Special Report, Agriculture Extension Service, Iowa State College, no. 18, pp. 56-77, 1956

[13] E. Rogers, The Diffusion of Innovations. First \& Fourth Editions, New York: Free Press, 1960 \& 1995.

[14] F. D. Davis, "Perceived usefulness, perceived ease of use, and user acceptance of information technology". MIS Quarterly, vol. 13, no. 3, pp. 319-340, 1989

[15] D. Gefen and D. Straub, "The Relative Importance of Perceived Ease of Use in IS Adoption: A Study of E-Commerce Adoption". Journal of the association of information, vol. 1, no. 8, 2000.

[16] F. D. Davis, "Acceptance of Information Technology: Research Progress, Current Controversies, and Emerging Paradigms". Workshop on HCI Research in MIS, Walton College of Business, University of Arkansas, December 8, 2007.

[17] Y. Malhotra and D. F. Galletta, "Extending the technology acceptance model to account for social influence: theoretical bases and empirical validation". Proceedings of $32^{\text {nd }}$ HICSS, pp.6-19, 1999.

[18] K. Mathieson, E. Peacock, and W.W. Chin, "Extending the technology acceptance model: the influence of perceived user resources". ACM SIGMIS Database archive, vol. 32 , no. 3, Special issue on adoption, diffusion, and infusion of IT , pp. 86-112, 2001.

[19] V. Venkatesh and F.D. Davis, "A theoretical extension of the technology acceptance model: Four longitudinal field studies". Management Science, vol. 46, no. 2, pp. 186-204, 2000.

[20] N. Venkatesh, M. G. Morris, G. B. Davis, and F.D. Davis, "User acceptance of information technology: Toward a unified view". MIS Quarterly, vol. 27, no. 3, pp. 425-478, 2003.

[21] N. Lu and P.M.C. Swatman, "The MobiCert project: Integrating Australian organic primary producers into the grocery supply chain". Journal of Manufacturing Technology Management, vol. 20, no. 6, pp. 887-905, 2009.

[22] C.O. Seneler, N. Basoglu, and T.U. Daim, "A Taxonomy for Technology Adoption: A Human Computer Interaction Perspective". PICMET 2008 Proceedings, South Africa, 2008.

[23] A. Jain and B. S. Hundal, "Factors Influencing Mobile Services Adoption in Rural India”. Asia Pacific Journal of Rural Development, vol. 17, no. 1, pp. 17-28, 2007.

[24] K. Kalba, "The Adoption of Mobile Phones in Emerging Markets: Global Diffusion and the Rural Challenge". International Journal of Communication, vol. 2, pp. 631-661, 2008.

[25] S. Sangwan and L. F. Pau, "Diffusion of Mobile Phones in China". ERIM Report Series, ERS-2005-056-LIS, 2005.

[26] J. V. Biljon and P. Kotzé,"Modeling the factors that influence mobile phone adoption". Proceedings of the 2007 annual research conference of the South African ICSIT on IT research in developing countries, South Africa, pp. 152 - 161, 2007.

[27] P. A. Geroski, "Models of Technology Diffusion". Research Policy, no. 29 , pp. 603-626, 2000.

[28] B. Hobijn and D. Comin, "Cross-Country Technology Adoption: Making the Theories Face the Facts". FRB NY Staff Report, no. 169, June, 2003.

[29] C. Sinha, "Effect of Mobile Telephony on Empowering Rural Communities in Developing Countries". IRFD Conference on Digital Divide, Tunisia, 2005.

[30] M. T. Dishaw and D. M. Strong, "Extending the technology acceptance model with task-technology fit constructs". Information \& Management, vol. 36, no. 1, pp. 9-21, 1999

[31] B. Kargin and N. Basoglu, "Factors Affecting the Adoption of Mobile Services". PICMET Proceedings, Portland, USA, 5-9 August, 2007.

[32] Y. Li, Z., T. Fu , and H. Li, "Evaluating factors affecting the adoption of mobile commerce in agriculture : an empirical study". New Zealand Journal of Agricultural Research, vol. 50, no. 5, pp. 12131218, 2007.

[33] S. Sarker and J. D. Wells, "Understanding mobile handheld device use and adoption". Communications of the ACM, vol. 46, no. 12, pp. 35-40, 2003. 
[34] V. Venkatesh, "Determinants of perceived ease of use: Integrating control, intrinsic motivation, and emotion into the technology acceptance model". Information Systems Research, vol. 11, no. 4, pp. $342-365,2000$

[35] H. Karjaluoto, J. Karvonen, M. Kesti, T. Koivumäki, M. Manninen, J. Pakola, A. Ristola, and J. Salo, "Factors Affecting Consumer Choice of Mobile Phones: Two Studies from Finland". Journal of Euromarketing, vol. 14, no. 3, 2005.

[36] S. Kalish, "A New Product Adoption Model with Price, Advertising, and Uncertainty". Management Science, vol. 31, no. 12, pp. 1569 $1585,1985$.

[37] P. Kotler and G. Armstrong, Principles of Marketing. Englewood Cliffs, NJ: Prentice Hall, 1994.

[38] C. R. Doss, "Understanding farm level technology adoption: Lessons learned from CIMMYT's micro surveys in Eastern Africa". CIMMYT Economics Working Paper, 03-07. Mexico, D.F.: CIMMYT, 2003.

[39] R. Cook, Awareness and Influence in Health and Social Care: How you can really make a difference. Radcliffe Publishing Ltd. pp. 256, 2006.

[40] M. Fishbein, and I. Ajzen, Belief, Attitude, Intention and Behavior: An Introduction to Theory and Research. MA : Addison-Wesley, 1975.

[41] M. Qingfei, J. Shaobo, and Q. Gang, "Mobile Commerce User Acceptance Study in China: A Revised UTAUT Model". Tsinghua Science and Technology, vol. 13, no. 3, 2008.

[42] J. B. Stiff and P. A. Mongeau, Persuasive communication (2nd ed.). USA: Guilford Press, 2003

[43] C. C. Wong and P. L. Hiew, "Diffusion of Mobile Entertainment in Malaysia: Drivers and Barriers". Proceedings of World Academy of Science, vol. 5, 2005.

[44] L. Hultberg, "Women Empowerment in Bangladesh: A Study of the Village Pay Phone Program". Thesis: Media and Communication Studies, School of Education and Communication (HLK) Jönköping University, Spring Term , 2008.

[45] J. Isham, "The Effect of Social Capital on Technology Adoption: Evidence from Rural Tanzania”. IRIS Center Working Paper, no. 235 2000.

[46] G. Hans, "Towards a Sociological Theory of the Mobile Phone". In: Sociology in Switzerland: Sociology of the Mobile Phone. Online Publications, Zuerich, March 2004 (Release 3.0). http://socio.ch/mobile/t_geser1.html.

[47] J. V. Biljon and K. Renaud, "A Qualitative Study of the Applicability of Technology, Acceptance Models to Senior Mobile Phone Users, Advances in Conceptual Modeling - Challenges and Opportunities". Lecture Notes in Computer Science, Germany: Springer, no. 5232, pp. 228-237, 2008.

[48] A. Vishwanath and G. M. Goldhaber, "An examination of the factors contributing to adoption decisions among late-diffused technology products". New Media \& Society, vol. 5, no. 4, pp. 547-572, 2003.

[49] P. DiMaggio and J. Cohen, "Information Inequality and Network Externalities: A Comparative Study of the Diffusion of Television and the Internet". The Economic Sociology of Capitalism, Working paper, no. 31, 2003.

[50] S. Mallenius, M. Rossi, and V. K. Tuunainen, "Factors affecting the adoption and use of mobile devices and services by elderly peopleresults from a pilot study". Proceeding of 6th Annual Global Mobility Roundtable, USA, 2007.

[51] D. Richardson, R. Ramirez, and M. Haq, "Grameen Telecom's Village Phone Programme: A Multi-Media Case Study". CIDA, Canada, 2000.

[52] Lisa A. Phillips, R. Calantone, Ming-Tung Lee, "International Technology Adoption: Behavior Structure, Demand Certainty and Culture". Journal of Business \& Industrial Marketing, vol. 9, no: 2, pp.16-28, 1994

[53] L. G. Schiffman and L.L. Kanuk, Consumer Behavior (9th ed). USA: Prentice-Hall, 2004.

[54] K. O. Fuglie and C. A. Kascak, "Adoption and diffusion of naturalresource-conserving agricultural technology". Review of Agricultural Economics, vol. 23, no. 2, pp. 386-403, 2001.
[55] F. Sultan and L. Chan, "Object-Oriented Computing in Software Companies". IEEE Transaction on Engineering Management, vol. 47, no. 1, 2000.

[56] L. Wei and M. Zhang, "The adoption and use of mobile phone in rural China: A case study of Hubei, China", Telematics and Informatics archive, vol. 25 , no. 3 , pp. 169-186, 2008.

[57] H. Gatignon and T.S. Robertson, "Technology Diffusion: An Empirical Test of Competitive Effects", The Journal of Marketing, vol. 53, pp. 35-49, 1989.

[58] S. L. Huff and M. C. Munro, "Managing Micro Proliferation". Journal of Information Systems Management, vol. 6, no. 4, pp. 72-75, 1989.

[59] J. Lu, J.E. Yao, and C. S. Yu, "Personal innovativeness, social influences and adoption of wireless Internet services via mobile technology”. Journal of Strategic Information Systems, vol. 14, no. 3 , 2005.

[60] K. Renaud and J. V. Biljon, "A Qualitative Study of the Applicability of Technology, Acceptance Models to Senior Mobile Phone Users, Advances in Conceptual Modeling - Challenges and Opportunities". Lecture Notes in Computer Science, Berlin / Heidelberg : Springer, vol. 5232. SAICSIT, 2008.

[61] Y. Lu, Z. Deng, and B. Wang, "An Empirical Study on Chinese Enterprises" Adoption of Mobile Services, 1-4244-1312-5/07/, IEEE, 2007.

[62] C. Carlsson, K. Hyvönen, P. Repo, and P. Walden, "Adoption of Mobile Services across Different Technologies". 18th Bled eConference, Slovenia, June 6-8, 2005

[63] J. Donner, "The social and economic implications of mobile telephony in Rwanda: An ownership/access typology”. In P. Glotz, S. Bertschi \& C. Locke (Eds.), Thumb culture: The meaning of mobile phones for society, pp. 37-52, 2005.

[64] G. Walsham, "Interpretive case studies in IS research: nature and method". European Journal of Information Systems, vol. 4, pp. 74-81, 1995.

[65] R. K. Yin, Case Study Research: Design and Methods, Revised ed., Thousand Oaks, USA: Sage, 2003.

[66] A. D. Andrade, "Interpretive Research Aiming at Theory Building: Adopting and Adapting the Case Study Design". The Qualitative Report, vol. 14, no. 1, pp. 42-60, 2009

[67] B. J. Oates, Researching Information Systems and Computing, London: Sage Publications, 2006.

[68] B. G. Glaser and A. L. Strauss, The Discovery of Grounded Theory, New York, Aldine, 1967

[69] W. J. Orlikowski, "CASE Tools as Organizational Change: Investigating Incremental and Radical Changes in Systems Development”. MIS Quarterly, vol. 17, no. 3, 1993.

[70] J. Webster and R. Watson, "Analyzing the past to prepare for the future”. MIS Quarterly, vol. 26, no. 2, 2002.

[71] K. Banks, "Mobile Phones and the Digital Divide". PC World, IDG News Service, July 29, 2008. Available: http://www.pcworld.com/article/149075/mobile_phones_and the dig ital_divide.html.

[72] Asia's women in agriculture, environment and rural production: Bangladesh. Sustainable Development Department, Food and Agriculture Organization of the United Nations, 1997.

[73] Bangladesh: Female share of non-agricultural wage employment. The United Nations University (UNU)-Globalis, The Global Virtual University, $2003 \quad$ Available http://globalis.gvu.unu.edu/indicator_detail.cfm?IndicatorID $=62 \& \mathrm{Co}$ untry=BD

[74] A. R. Khan, R. W. Rochat, F. A. Jahan, and S. F. Begum, "Induced abortion in a rural area of Bangladesh". Studies in Family Planning, vol. 17, no. 2, pp. 95-99, 1986.

[75] E. R. Hilgard, "The trilogy of mind: Cognition, affection, and conation". Journal of the History of Behavioral Sciences, vol. 16, pp. 107-117, 1980. 